\title{
Mucopolysaccharides in suspensions of Treponema pallidum extracted from infected rabbit testes
}

\author{
J J van Der Sluis, G van DIJK, M BOER, E STOLZ, AND Th VAN JOOST \\ From the Department of Dermatovenereology, Faculty of Medicine, Erasmus University, Rotterdam, The \\ Netherlands
}

SUMMARY The amount and nature of mucopolysaccharides present in extraction fluids routinely obtained in the isolation procedure of Treponema pallidum from infected rabbit testes was investigated. The mean quantity of mucopolysaccharides extracted from both testes of groups of 10 rabbits was $3.09 \mathrm{mg}$ after infection for seven days and $26.88 \mathrm{mg}$ after infection for 12 days, while from the testes of uninfected rabbits a mean of $0.42 \mathrm{mg}$ was obtained. On electrophoresis the isolated mucopolysaccharides showed only one single band with the migration characteristics of hyaluronic acid. This band disappeared completely after pretreatment with hyaluronidase from bovine testes, which showed that during infection with $T$ pallidum increasing amounts of hyaluronic acid accumulate. They can, at least in part, be extracted by a gentle extraction procedure, suggesting that this material binds loosely. The amount of hyaluronic acid isolated 12 days after infection showed positive correlations with the wet weight of testes as well as the number of treponemes isolated; seven days after infection such correlations were not present.

\section{Introduction}

One of the microscopical features of tissues infected experimentally with Treponema pallidum is the interstitial siting of the infectious process, which has the appearance of loosely woven acellular areas resembling embryonic connective tissue. ${ }^{12}$ In these interstitial areas acid mucopolysaccharides seem to accumulate, as is shown by the presence of a substance which stains metachromatically with toluidine blue and related stains. ${ }^{13}$ The presence of this substance is especially pronounced in rabbits treated with cortisone. ${ }^{4}$ The metachromasia of such tissues can be abolished by pretreatment with hyaluronidase from bovine testes. ${ }^{13}$ In a chemical analysis of rabbit cutaneous syphilomas Rice found an increase in two types of acid mucopolysaccharide: the non-sulphated type was indistinguishable from hyaluronic acid, the sulphated type was identical to chondroitin sulphate C (chondroitin-6-sulphate). ${ }^{5}$ In 1963 Christiansen postulated the existence of a mucoid slime layer covering pathogenic treponemes, ${ }^{6}$ which could explain the presence of pathogenic treponemes in a host side by side with antitreponemal antibodies of

Address for reprints: Dr J J van der Sluis, Department of Dermatovenereology, Faculty of Medicine, Erasmus University, Rotterdam, The Netherlands

Accepted for publication 25 April 1984 high titre. In 1976 Zeigler et al presented an electron micrographic study of rabbit testicular tissue previously infected with Nichols pathogenic treponemes and of the treponemes extracted from such tissue. On staining with ruthenium red, both types of treponemes were seen to be surrounded by a layer of stained material, which probably consisted of acid mucopolysaccharides or closely related compounds. The extracted treponemes were covered with a much less thick and less regular layer of this material than treponemes present in tissue, which indicates that treponemes in vivo seem to be closely associated with the presence of acid mucopolysaccharide. This prompted us to investigate the possible presence and nature of mucopolysaccharides in treponemal suspensions used for in vitro studies.

\section{Materials and methods}

New Zealand white rabbits about six to eight months old were obtained from a commercial breeding farm. They were housed individually at $18-20^{\circ} \mathrm{C}$ and kept in quarantine for four weeks. The animals were clinically healthy. During the quarantine period the animals were vaccinated against Pasteurella multocida and treated against coccidia with sulphadimethoxine. They were given food free of antibiotics and water ad libidum. All animals used had negative serological reactions for syphilis. It was concluded that they were not suffering from infection with 
Treponema paraluis cuniculi. T pallidum (Nichols pathogenic strain) obtained in 1978 from $\mathrm{Dr} J \mathrm{~N}$ Miller, UCLA, Los Angeles, USA, was maintained by serial passage in rabbit testes. At weekly intervals, two rabbits were inoculated in both testes with $0.5 \mathrm{ml} T$ pallidum suspension, containing about $50 \times 10^{6}$ treponemes $/ \mathrm{ml}$. One rabbit was killed after seven days, the second after 12 days. The testes were removed and weighed. They were minced with scissors, and $1 \mathrm{ml}$ basal reduced medium ${ }^{8}$ containing $20 \%$ fetal calf serum (Flow Laboratories, Irvine, Ayrshire, Scotland) was added for each gram of wet testis. The treponemes were extracted from the testicular tissue by shaking for 45 minutes in an atmosphere of $95 \%$ nitrogen and $5 \%$ carbon dioxide. This extraction procedure was repeated several times as specified in the results section. All fluid extracted was centrifuged at $800 \times g$ for 10 minutes to sediment gross particulate matter. Part of this treponeme suspension was used for other purposes, the other part was centrifuged at $12000 \times g$ to remove most of the treponemes. This latter supernate, referred to as testicular extract, was used for estimations of acid mucopolysaccharides.

$T$ pallidum organisms were counted using microslides of $0.05 \mathrm{~mm}$ pathlength (ref 5005, Camlab, Cambridge). The microslide was filled with appropriately diluted treponeme suspension by capillary suction and stuck at both ends to a microscope slide with nail polish, which also closed the ends of the microslide. The number of treponemes present under the area of a square ocular micrometer was counted in 30 microscope fields. The area under the ocular micrometer had been measured previously using a stage micrometer. The number of treponemes $/ \mathrm{ml}$ suspension was calculated from the average number of treponemes present in the known volume in the microslide covered by the ocular micrometer. Uninfected testes were obtained from healthy rabbits of comparable age and were processed in the same way as infected testes.

\section{ISOLATION OF MUCOPOLYSACCHARIDE} Cetylpyridiniumchloride (CPC) (Sigma Chemical Co, St Louis, USA) was used to precipitate mucopolysaccharide. ${ }^{9}$ In preliminary experiments optimum conditions of temperature, concentration of CPC, final electrolyte concentration, and relative centrifugal force were assessed. Mucopolysaccharide was isolated as follows: $1 \mathrm{ml}$ of a $1 \%$ (w/v) CPC solution in twice distilled water was added to $2 \mathrm{ml}$ testicular extract, and the mixture was left undisturbed overnight (about 18 hours) at room temperature. The precipitates in the tubes were then collected by centrifugation at $1800 \times g$ for 15 minutes. The supernate was removed very carefully from the loose precipitate, which was suspended in $3 \mathrm{ml}$ precooled $\left(4^{\circ} \mathrm{C}\right)$ absolute ethanol containing $10 \mathrm{~g}$ potassium acetate/litre. After at least 24 hours at $4^{\circ} \mathrm{C}$ the precipitate was collected by centrifuging at $1800 \times g$ for 15 minutes at $4^{\circ} \mathrm{C}$. The supernate was decanted carefully and the precipitate dried in vacuo. The precipitate was then dissolved in $0.1 \mathrm{ml} 2 \mathrm{~mol} / 1$ sodium hydroxide solution, sometimes with warming in a $37^{\circ} \mathrm{C}$ waterbath, and $1.9 \mathrm{ml}$ bidistilled water was added and the contents of the tubes thoroughly mixed. These solutions were used to measure the mucopolysaccharide content of the testicular extracts. As shown by electrophoresis, these solutions still contained a small amount of glycoproteins precipitated by CPC.

Mucopolysaccharide precipitates free of protein were prepared from testicular extracts as follows: $2 \mathrm{ml}$ extract was mixed with $1 \mathrm{ml} 15 \%$ (w/v) trichloroacetic acid in twice distilled water. After four hours at $4^{\circ} \mathrm{C}$ the mixture was centrifuged at $1800 \times g$ for 15 minutes and the precipitate washed three times with $1 \mathrm{ml} 5 \%$ trichloroacetic acid solution. Three volumes of absolute ethanol were added to the combined supernate and washing fluids. After at least 18 hours at $4^{\circ} \mathrm{C}$ the gelatinous precipitate was collected by centrifuging at $1800 \times g$ for 15 minutes at $4^{\circ} \mathrm{C}$, the supernate removed, and the precipitate dried in vacuo. The precipitate was then dissolved in $1 \mathrm{ml} 0.075 \mathrm{~mol} / 1$ sodium chloride solution. This meant a twofold concentration compared with parent testicular extract. Similar amounts of mucopolysaccharide were obtained from the same testicular extract with both isolation methods.

\section{CALCULATION OF CONCENTRATION OF MUCOPOLYSACCHARIDE}

The concentration of the mucopolysaccharide was calculated from its hexuronic acid content using the borate modification ${ }^{10}$ of the carbazol reaction. ${ }^{11}$ This reaction was performed in a one step modification as described by Pennock. ${ }^{9}$ Briefly, $0.2 \mathrm{ml}$ of the mucopolysaccharide solution under investigation was mixed in duplicate tubes with $0.2 \mathrm{ml}$ of a solution of $1.25 \mathrm{~g}$ carbazol (Merck) in 1 litre absolute ethanol. To this mixture $2 \mathrm{ml}$ borate-sulphuric acid reagent $(0.5 \mathrm{~g}$ sodium tetraborate (Merck, Darmstadt, West Germany) in 1 litre concentrated sulphuric acid stored at $4^{\circ} \mathrm{C}$ was added and thoroughly mixed. The tubes were placed in a vigourously boiling waterbath for at least seven minutes and then cooled. The extinction was read on a spectrophotometer at $530 \mathrm{~nm}$ against a blank prepared from the extraction medium by similar treatment as was used for the testicular extract. The concentration of mucopolysaccharide was calculated using a standard 
curve made with chondroitin sulphate (Sigma, mixed isomers from whale and shark cartilage).

ELECTROPHORESIS OF MUCOPOLYSACCHARIDES Protein free mucopolysaccharide solutions were subjected to electrophoresis as described by Breen et $a^{12}$ on cellulose acetate strips (Cellogel, Chemetron, Milan, Italy). The electrolyte system for electrophoresis consisted of a mixture of equal parts of $0.05 \mathrm{~mol} / \mathrm{l}$ lithium chloride solution and $0.01 \mathrm{~mol} / 1$ hydrogen chloride solution ( $\mathrm{pH} 2)$. Samples of the solutions under investigation were applied to presoaked electrophoresis strips, and current was passed at $4 \mathrm{~mA} /$ strip for 25 minutes. The strips were stained, with $1 \%(\mathrm{w} / \mathrm{v})$ alcian blue $8 \mathrm{GX}$ dissolved in a mixture of equal parts of absolute

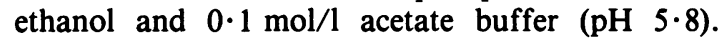
Excess stain was removed in a mixture of $5 \%(\mathrm{v} / \mathrm{v})$ acetic acid and $10 \%(\mathrm{v} / \mathrm{v})$ ethanol in bidistilled water. The strips were clarified in anhydrous methanol for one minute followed by one minute in $20 \%$ acetic acid in methanol. The strips were applied to glass slides and dried. Mucopolysaccharide standards used in the electrophoresis procedure were hyaluronic acid (Sigma, grade IV), chondroitin sulphate (Sigma mixed isomers, grade III), and sodium heparin, obtained from the University Hospital dispensary. All standards were dissolved at $1.5 \mathrm{~g} / 1$ in the extraction medium used to extract rabbit testes. These solutions were processed in the same way as described for the preparation of mucopolysaccharide solutions free of protein. Finally, they were dissolved in $1 \mathrm{ml} 0.075 \mathrm{~mol} / 1$ sodium chloride solution. Serial dilutions of these solutions were used to measure the detection limit of hyaluronic acid and chondroitin sulphate on electrophoresis, which appeared to be $0 \cdot 15 \mathrm{~g} / 1$ for both.

TREATMENT WITH HYALURONIDASE

A volume of $0.5 \mathrm{ml}$ mucopolysaccharide solution in $0.075 \mathrm{~mol} / 1$ sodium chloride was diluted to $2 \mathrm{ml}$ by adding $0.1 \mathrm{~mol} / 1$ acetate buffer ( $\mathrm{pH} \mathrm{5).} \mathrm{A} \mathrm{volume} \mathrm{of}$ $1 \mathrm{ml}$ hyaluronidase solution (Sigma, hyaluronidase from bovine testes, grade IV, $810 \mathrm{NV}$ units $/ \mathrm{mg}$ ), containing $0.5 \mathrm{~g} / 1$ and dissolved in the same acetate buffer, was added and the mixture placed in a $56^{\circ} \mathrm{C}$ waterbath for 30 minutes with occasional shaking. The reaction was stopped by the addition of $1.5 \mathrm{ml}$ $15 \%$ trichloroacetic acid solution. The mixture was left undisturbed for four hours at $4^{\circ} \mathrm{C}$ and subsequently subjected to the isolation procedure for mucopolysaccharide solutions free of protein as described. Controls were prepared in the same way without the addition of hyaluronidase.

\section{ESTIMATION OF PROTEIN}

Protein was measured by the biuret reaction against the appropriate blanks. Protein concentrations were calculated using bovine serum albumin as a standard.

\section{STATISTICAL ANALYSIS}

Statistical procedures used were the Wilcoxon nonparametric test for the calculation of significance of differences and Spearman's correlation test.

\section{Results}

In the first experiments we investigated the yield of mucopolysaccharide in relation to the number of extractions from minced testicular tissue. Seven such extractions were performed on testes obtained from three uninfected rabbits, three rabbits infected for seven days, and three rabbits infected for 12 days. Table I shows the mean amount of carbazol positive material obtained in each extraction from these three groups of rabbits. In uninfected rabbits the amount of mucopolysaccharide obtained was less than $0.05 \mathrm{mg}$ after the first extraction. In the rabbits infected for seven days most of the mucopolysaccharide was obtained from the first two oxtractions with further extractions yielding a plateau of small amounts. In the rabbits infected for 12 days such a plateau was obtained after the third extraction. The height of these plateaux differed considerably between all three groups of rabbits. From table I it can be seen that the first three extractions yielded $62.5 \%$ of the total extracted from uninfected rabbits, $65.9 \%$ of the total from rabbits infected for seven days, and $87.5 \%$ of the total from rabbits infected for 12 days. In each group two thirds or more of the total amount was present in the first extraction fluid. From these results we decided to

TABLE I Mucopolysaccharide obtained from repeated extractions from testicular tissue of uninfected rabbits and those infected with $T$ pallidum for seven and 12 days (amounts in $\mathrm{mg}$ )

\begin{tabular}{|c|c|c|c|c|c|c|c|c|c|c|}
\hline \multirow{2}{*}{$\begin{array}{l}\text { Rabbits (3 in } \\
\text { each group) }\end{array}$} & \multicolumn{7}{|c|}{ Amount obtained from extraction: } & \multirow{2}{*}{$\begin{array}{l}\text { Total } \\
\text { amount } \\
\text { obtained }\end{array}$} & \multicolumn{2}{|c|}{ Amount (\% of total) obtained from: } \\
\hline & 1 & 2 & 3 & 4 & 5 & 6 & 7 & & Extractions 1-3 & Extractions 4-7 \\
\hline $\begin{array}{l}\text { Uninfected } \\
\text { Infected } 7 \text { days } \\
\text { Infected } 12 \text { days }\end{array}$ & $\begin{array}{r}0 \cdot 19 \\
1 \cdot 48 \\
20 \cdot 00\end{array}$ & $\begin{array}{l}0 \cdot 05 \\
0 \cdot 46 \\
6 \cdot 81\end{array}$ & $\begin{array}{l}0 \cdot 01 \\
0 \cdot 19 \\
3 \cdot 08\end{array}$ & $\begin{array}{l}0.02 \\
0.21 \\
1 \cdot 09\end{array}$ & $\begin{array}{l}0.02 \\
0.24 \\
1 \cdot 00\end{array}$ & $\begin{array}{l}0 \cdot 04 \\
0 \cdot 29 \\
1 \cdot 10\end{array}$ & $\begin{array}{l}0.07 \\
0.36 \\
1.09\end{array}$ & $\begin{array}{r}0 \cdot 40 \\
3 \cdot 23 \\
34 \cdot 17\end{array}$ & $\begin{array}{r}0.25(62.5) \\
2.13(65 \cdot 9) \\
29.89(87.5)\end{array}$ & $\begin{array}{l}0 \cdot 15(37 \cdot 5) \\
1 \cdot 10(34 \cdot 1) \\
4 \cdot 28(12 \cdot 5)\end{array}$ \\
\hline
\end{tabular}


TABLE II Weight of testes from uninfected rabbits and those infected with $T$ pallidum for seven and 12 days, number of treponemes obtained from one extraction, and amounts of mucopolysaccharide and protein obtained from three extractions of testes (figures are means (SD))

\begin{tabular}{|c|c|c|c|c|c|c|}
\hline \multirow{2}{*}{$\begin{array}{l}\text { Rabbits (10 in } \\
\text { each group) }\end{array}$} & \multirow{2}{*}{$\begin{array}{l}\text { Weight of } \\
\text { testes (g) }\end{array}$} & \multirow{2}{*}{$\begin{array}{l}\text { No of treponemes } \\
(\times 10-7)\end{array}$} & \multicolumn{2}{|c|}{ Amount of mucopolysaccharide: } & \multicolumn{2}{|c|}{ Amount of protein: } \\
\hline & & & Total (mg) & $m g / g$ testis & Total (mg) & $m g / g$ testis \\
\hline $\begin{array}{l}\text { Uninfected } \\
\text { Infected } 7 \text { days } \\
\text { Infected } 12 \text { days }\end{array}$ & $\begin{array}{r}5 \cdot 63(1 \cdot 21) \\
13 \cdot 03(2 \cdot 14) \\
14 \cdot 65(2 \cdot 83)\end{array}$ & $\begin{array}{l}107 \cdot 2(51 \cdot 2) \\
247 \cdot 0(141 \cdot 4)\end{array}$ & $\begin{array}{rr}0.42 & (0.15) \\
3.09 & (2 \cdot 50) \\
26.88 & (12.80)\end{array}$ & $\begin{array}{l}0.08(0.03) \\
0.23(0.18) \\
1.79(0.67)\end{array}$ & $\begin{array}{r}97 \cdot 4(20 \cdot 0) \\
238 \cdot 3(55 \cdot 8) \\
272 \cdot 8(89 \cdot 1)\end{array}$ & $\begin{array}{l}16 \cdot 6(2 \cdot 0) \\
17 \cdot 2(3 \cdot 2) \\
18 \cdot 2(3 \cdot 2)\end{array}$ \\
\hline
\end{tabular}

perform three extractions for further work on the isolation of mucopolysaccharide.

Table II shows the results of three repeated extractions from the testes of 10 rabbits in each group. The mean total amount of mucopolysaccharide isolated from the uninfected rabbits was $0.42 \mathrm{mg}$, from rabbits infected for seven days it was $3.09 \mathrm{mg}$, and from rabbits infected for 12 days it was $26.88 \mathrm{mg}$. Comparison with uninfected rabbits shows a 7-4-fold increase during the first seven days of infection and a 64-fold increase after 12 days - that is, a large increase between days 7 and 12. Table II also shows that the wet weight of testes increased during infection with $T$ pallidum. During the first seven days the weight of testes increased $2 \cdot 4$-fold $(2 \alpha<0 \cdot 01)$, but there was only a slight and not significant further increase between days 7 and 12 . When the amount of mucopolysaccharide extracted was related to the wet weight of testes $(\mathrm{mg} / \mathrm{g})$ there was a threefold increase in mucopolysaccharide by day 7 and a 22 -fold increase by day 12 . The mean number of extracted treponemes increased $2 \cdot 3$-fold between days 7 and 12. The figure shows that on electrophoresis the extracted mucopolysaccharide consistently showed one single band with the migration characteristics of hyaluronic acid. The extracts obtained from rabbits infected for 12 days contained a sufficient quantity of material to give a clearly visible band immediately after staining with alcian blue. The extracts from the rabbits infected for seven days in most cases contained less mucopolysaccharide than the detectable amount for hyaluronic acid $(0 \cdot 15 \mathrm{~g} / \mathrm{l})$. In these cases concentration was necessary to obtain a visible spot. This band also had the migration characteristics of hyaluronic acid. In none of the extracts was a band obtained that corresponded to chondroitin sulphate. This indicates that in the parent extract the concentration of chondroitin sulphate was below $0.075 \mathrm{~g} / \mathrm{l}$ and presumably much lower, as electrophoresis of concentrated extracts also failed to show chondroitin sulphate. The extracts from uninfected rabbit testes did not yield a visible spot after electrophoresis and staining. In all cases the band disappeared completely after pretreatment of the isolated substance with hyaluronidase from bovine testes. Although this type of hyaluronidase splits not only hyaluronic acid but also other types of mucopolysaccharide, ${ }^{13}$ we conclude from the method of isolation, the reactivity with the carbazol reagent, the electrophoretic mobility, and the digestibility with hyaluronidase that the isolated substance was hyaluronic acid.

The amount of hyaluronic acid obtained from rabbits infected for 12 days showed a positive correlation with the wet weight of testes $(r=0.68)$ as well as the number of $T$ pallidum organisms extracted $(r=0.87)$; these correlations were not present in rabbits infected for seven days.

The amount of protein present in the testicular extract is shown in table II. The data indicate that protein accumulated in the infected testes during treponemal infection. Although the total amount increased with the duration of infection, the amount of protein per gram of wet testis showed little difference between the three groups of rabbits. The electrophoretic pattern of these proteins, which were present in extracts prepared in the absence of fetal calf serum, showed the characteristics of rabbit serum proteins as no extra bands were present (data not shown).

\section{Discussion}

We have shown that the extraction of $T$ pallidum from infected rabbit testes with an aqueous medium yielded a mucopolysaccharide with the characteristics of hyaluronic acid. The amounts isolated from infected testes were well above those obtained from normal testes, while the infected testes yielded an increasing amount the longer the duration of the experimental infection. Sulphated mucopolysaccharides have also been found to be formed during the syphilitic process in rabbit skin ${ }^{5}$ and testes (van der Sluis et al, unpublished observation). Using a quantitative destructive technique, Rice found almost equal amounts (about $20 \mathrm{mg}$ ) of hyaluronic acid and chondroitin sulphate per gram of wet syphilitic tissue from rabbits that had not been treated with cortisone. The detection of only hyaluronic acid in the extracts obtained with the mild 


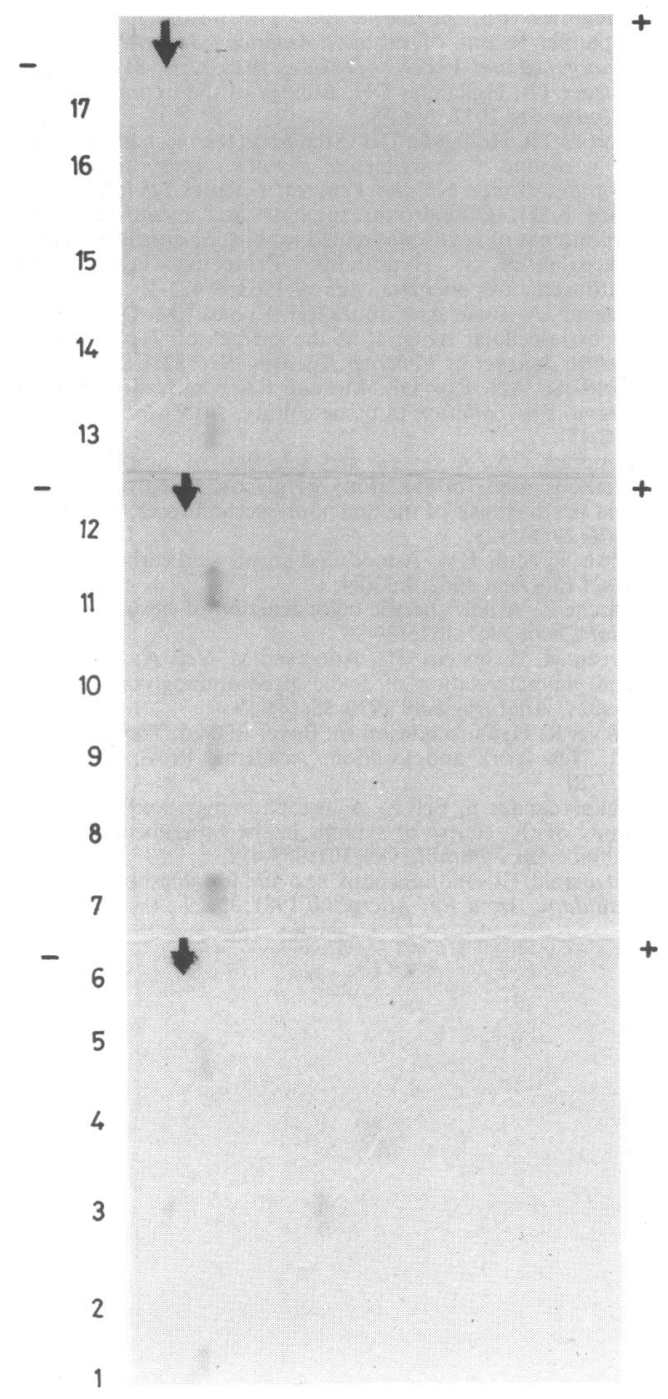

FIGURE Cellulose acetate electrophoresis of mucopolysaccharide standards and mucopolysaccharide extracted from uninfected rabbit testes and those infected with $T$ pallidum for 7 and 12 days, before and after treatment with hyaluronidase, as follows: Hyaluronic acid standard (lane 1); hyaluronic acid standard after treatment with hyaluronidase (lanes 2 and 14); chondroitin sulphate standard (lane 3); sodium-heparin standard (lane 4); protein free mucopolysaccharide from day 12 infection (lanes 5, 7, 9, and 11); mucopolysaccharide from previous lanes after treatment with hyaluronidase (lanes 6, 8, 10, and 12); hyaluronic acid standard subjected to the hyaluronidase procedure but without hyaluronidase added (lane 13); mucopolysacharide from uninfected testes (no spot visible) (lanes 15 and 16); and mucopolysaccharide from day 7 infection (faint spot visible). Arrows indicate the application lines. extraction procedure used here suggests that for different types of mucopolysaccharide different binding types exist within the infected testicular tissue, with loose binding or even simple deposition of hyaluronic acid, while the sulphated mucopolysaccharides seem to be more firmly incorporated into the testicular tissue. Few quantitative data are available on the amount of hyaluronic acid present in syphilitic tissue. Millonig, cited by Turner and Hollander ${ }^{3}$ isolated $1 \mathrm{mg}$ hyaluronic acid per gram of wet cutaneous syphiloma tissue from rabbits not treated with cortisone. However, neither the methods of isolation nor of identification of this hyaluronic acid was reported. As already mentioned, Rice found $18.5 \mathrm{mg}$ of mucopolysaccharide like hyaluronic acid per gram of wet tissue. ${ }^{5}$ Although it is questionable whether cutaneous syphilomas can be compared with infected testes, the amount found by Millonig is confirmed by our results. The data of Rice suggest, however, that it is quite possible that only part of the hyaluronic acid present was isolated by our method.

We showed that the testes increased in weight during the experimental infection with $T$ pallidum. A similar increase in weight was reported by BakerZander and Sell. ${ }^{14}$ In this present study the increase in weight occurred almost completely during the first seven days of infection; during the following five days there was no further increase in the weight of testes. The oedematous character of syphilitic tissue suggests that a large part of the increase in weight was caused by the increased ability of these tissues to retain fluid. This was reflected in the presence of increasing amounts of rabbit serum proteins in the testicular extracts, which were almost constant in the three groups of rabbits when related to the wet weight of testes. Because of their water binding capacity, the accumulation of mucopolysaccharides in infected tissue might play a part in the increasing testes weight. The amounts of hyaluronic acid isolated during the infection period studied, however, deviated from the pattern of increasing testes weight. Only moderate amounts were obtained after the first seven days when the largest increase in testes weight was found. During the following five days no further increase in the weight of testes was noted but the amount of extractable mucopolysaccharides increased almost eightfold. Assuming that mucopolysaccharides play a major part in the increase in weight, these results suggest that the production of loosely bound mucopolysaccharide was preceded by the formation of more firmly bound mucopolysaccharide, which was responsible for the large increase in the weight of testes during the first seven days.

At present it is not clear whether the treponemes produce the mucopolysaccharides or only stimulate 
their production by host tissue cells. The latter possibility seems feasible as recent work has shown that pathogenic $T$ pallidum attaches in vitro to many types of cultured human and animal cells. ${ }^{15}$ It may well be that the newly formed mucopolysaccharides are produced by fibroblasts as a result of stimulation through treponemal attachment to them. This attachment might also result in incomplete extraction of treponemes, especially during the early stages of the infection. After 12 days of infection, positive correlations were present between the amount of extracted hyaluronic acid on the one hand and the wet weight of testes and the number of extracted treponemes on the other. Incomplete extraction of hyaluronic acid or treponemes, or both, might be the reason that such correlations were not present after seven days of infection.

Our results show that suspensions of $T$ pallidum derived from rabbits contain hyaluronic acid. As $T$ pallidum seems to be closely associated with the presence of mucopolysaccharide in vivo, the awareness of the presence of hyaluronic acid in these treponemal suspensions may be of practical importance in vitro studies.

\section{References}

1. Scott V, Dammin GJ. Morphologic and histochemical sequences in syphilitic and in tuberculous orchitis in the rabbit. American Journal of Syphilis, Gonorrhea and Venereal Diseases 1954;38: 189-202.
2. Gregoriew PS, Jarishewa KG. The histologic structure of syphilitic lesions of rabbits. American Journal of Syphilis, Gonorrhea and Venereal Diseases 1928; 12:67-81.

3. Turner TB, Hollander DH. Biology of the treponemes. WHO Monogr Ser 1957, No 35.

4. Turner TB, Hollander DH. Studies on the mechanism of action of cortisone in experimental syphilis. American Journal of Syphilis, Gonorrhea and Venereal Diseases 1954;38:371-87.

5. Rice FAH. Chondroitin sulphate and hyaluronic acid in syphilomas of cortisone-treated rabbits. Science 1956; 124:256.

6. Christiansen S. Hypothesis. Protective layer covering pathogenic treponemata. Lancet 1963; ii:423-4.

7. Zeigler JA, Jones AM, Jones RH, Kubica KM. Demonstration of extra-cellular material at the surface of $T$ pallidum cells. British Journal of Venereal Diseases 1976;52: 1-8.

8. Fieldsteel AH, Cox DL, Moeckli RA. Cultivation of virulent Treponema pallidum in tissue culture. Infect Immun 1981;32: 908-15.

9. Pennock CA. A review and selection of simple laboratory methods used for the study of glycosaminoglycan excretion and the diagnosis of the mucopolysaccharidoses. J Clin Pathol 1976; 29: 111-23.

10. Bitter F, Muir HM. A modified uronic acid carbazol reaction. Anal Biochem 1962;4:330-4.

11. Dische $Z$. A new specific color reaction of hexuronic acids. $J$ Biol Chem 1947; 167; 189-98.

12. Breen M, Weinstein HG, Anderson M, Veis A. Microanalysis and characterization of acidic glycosaminoglycans in human tissues. Anal Biochem 1970; 35: 146-59.

13. Meyer K. Hyaluronidases. In: Boyer PD, ed. The enzymes. 3rd ed. New York and London: Academic Press, 1971; vol V: 307-20.

14. Baker-Zander S, Sell S. A histopathologic and immunologic study of the course of syphilis in the experimentally infected rabbit. Am J Pathol 1980;101:387-414.

15. Fitzgerald FJ. Pathogenesis and immunology of Treponema pallidum. Annu Rev Microbiol 1981;35:29-54. 